\title{
POLÍTICAS PÚBLICAS: ABORDAGENS ACERCA DA ALTERAÇÃO DE NOME E DE GÊNERO DE PESSOAS TRANS
}

\section{PUBLIC POLICY: APPROACHES ABOUT CHANGE OF NAME AND GENDER OF TRANSPERSONS}

Francisco Antonio Vieira Cordeiro* Sandramor do Amaral Ferreira** Maria Geralda de Miranda***

\begin{abstract}
Resumo: O presente artigo tem como objetivo realizar uma abordagem sobre a possibilidade de pessoas transexuais conseguirem realizar a alteração do nome e do sexo no Registro Civil. A importância do assunto se faz necessária pelo fato de que atualmente a alteração do nome e do sexo no registro civil é uma forma de atender ao princípio da dignidade da pessoa humana. Para atingirmos o objetivo proposto, utilizaremos a pesquisa bibliográfica realizada em livros, periódicos especializados, além de outras publicações, com dados relacionados ao assunto em estudo. Pelo fato do presente trabalho ser de caráter interdisciplinar, nos basearemos no Pensamento Pós-Estruturalista, com suas expansões pelos Estudos de Gênero e a Teoria queer, que tem contribuído com as reflexões sobre gênero, corporeidade, sexualidade, além das discussões identitárias e sociais da contemporaneidade.
\end{abstract}

Palvras-chave: Gênero. Transexualidade. Registro Civil. Nome Social.

Abstract: The aim of this article is to analyze the possibility of transsexuals being able to change their names and sex in the Civil Registry. The importance of the subject is made necessary by the fact that currently the change of name and sex in the civil registry is a way of meeting the principle of the dignity of the human person. In order to reach the proposed objective, we will use bibliographical research carried out in books, specialized periodicals, as well as other publications, with data related to the subject under study. Because the present work is of an interdisciplinary nature, we will base ourselves on Post-Structuralist Thought, with its expansions by Gender Studies and Queer Theory, which have contributed to the reflections on gender, corporeality, sexuality, beyond the identity and social discussions of contemporaneity.

\footnotetext{
* Mestrando em Desenvolvimento Local, Centro Universitário Augusto Motta. E-mail: frcord@gmail.com.

** Mestranda em Desenvolvimento Local, Centro Universitário Augusto Motta. E-mail: sandramorcarpe.diem@hotmail.com

*** Mestre em Literatura Comparada com ênfase nos estudos culturais pela Universidade Federal Fluminense (UFF) e Doutora em Letras com ênfase em estudos pós-coloniais, também pela UFF. Professora do Programa de Pós-Graduação em Desenvolvimento Local, do Centro Universitário Augusto Motta, UNISUAM.
} 
Keywords: Gender. Transsexuality. Civil Registration. Social Name.

\section{INTRODUÇÃO}

As tentativas dos indivíduos transexuais de buscar um nome condizente com sua identidade têm chegado a destinos diferentes no Brasil, visto que ainda não existe uma legislação específica que aborde o assunto. Desse modo, o presente artigo tem como objetivo realizar uma abordagem sobre a possibilidade de pessoas transexuais conseguirem realizar a alteração do nome e do sexo no Registro Civil. Trata-se de um estudo que perpassa as relações oriundas de identidade de gênero. A importância do presente estudo se faz necessária pelo fato de que atualmente a alteração do nome e do sexo no registro civil vislumbra uma forma de atender ao princípio da dignidade da pessoa humana, que está inserida na Constituição Federal de 1988, como direito fundamental.

\section{TRANSEXUALIDADE: UMA EXPERIÊNCIA IDENTITÁRIA}

Transexualidade é a condição sexual da pessoa que rejeita sua identidade genética e a própria anatomia de seu gênero, identificando-se psicologicamente com o gênero oposto. Neste contexto, podemos dizer que transexual "é aquele indivíduo biologicamente perfeito, mas acredita pertencer ao sexo contrário à sua anatomia" (SÁ; NAVES, 2006, p. 227).

A transexualidade é um componente que revela "o caráter fluído e instável das identidades sexuais" (LOURO, 2004, p.31). Os corpos artificialmente edificados indicam, concreta e simbolicamente, as possibilidades de proliferação e multiplicação das identidades de gênero e das sexualidades (BENTO, 2006).

Os processos de estigmatização que os transexuais sofrem são decorrentes do rompimento com os modelos previamente dados pela normatização, ficando com isso, marcados negativamente e desprovidos de direitos a ter direitos, o chamado "corpo abjeto". 
Butler (2003) posiciona as mulheres transexuais no plano do abjeto, corpos expostos às várias formas de violência cuja existência parece não importar. De fato, importam, conquanto os abjetos precisam estar lá, ainda que numa "higiênica" distância, para demarcar as fronteiras da normalidade, de sorte que

O abjeto designa aqui precisamente aquelas zonas "invisíveis", inabitáveis da vida social que, sem dúvida, estão densamente povoadas por aqueles que não gozam da hierarquia dos sujeitos, mas cuja condição de viver sob o signo do "invisível" é necessária para circunscrever a esfera dos sujeitos (BUTLER, 2003, p. 19).

Segundo Bento (2008), a transexualidade é uma experiência identitária, caracterizada pelo conflito com as normas de gênero. Isto é, para os interesses da discussão desse trabalho, a mulher transexual é aquela que, a despeito de ter nascido com pênis e aparelho reprodutor masculino, possui identidade de gênero feminina, se reconhece enquanto mulher e deve, portanto, ser tratada como tal.

Portanto, entende-se que as instituições sociais esvaziam de qualquer humanidade os transexuais, invisibilizando-os de seus direitos e de sua cidadania.

\section{SEXO E GÊNERO}

Para Butler (2012), a dicotomia sexo/gênero se apresenta como alicerce de fundação da política feminista, partindo da ideia de que sexo é algo natural e gênero é produto da construção social. Para a autora, o sexo natural não é o determinante de se dizer que o "homem" pertença a um corpo masculino ou que a expressão "mulher" signifique que seu corpo seja feminino.

A autora vai mais além, quando aponta para a ideia de que gênero quando considerado independente e não se apresentar como sistema binário, reflete ou está restrito ao sexo. Por esse víeis, as expressões "homem" e "masculino" poderiam estar tanto para um corpo feminino quanto para um masculino e vice-versa.

A partir dessas premissas, a autora constrói sua argumentação sobre essa dualidade:

Se o sexo é, ele próprio, uma categoria tomada em seu gênero, não faz sentido definir o gênero como a interpretação cultural do sexo. O gênero não deve ser meramente concebido como a inscrição cultural de significado num sexo previamente dado (uma concepção jurídica); tem de designar 
também o aparato mesmo de produção mediante o qual os próprios sexos são estabelecidos. Resulta daí que o gênero não está para a cultura como o sexo para a natureza; ele também é o meio discursivo/cultural pelo qual 'a natureza sexuada' ou 'um sexo natural' é produzido e estabelecido como 'pré-discursivo', anterior à cultura, uma superfície politicamente neutra sobre a qual age a cultura (BUTLER, 2012, p. 25).

Nessa perspectiva, Butler (2012) desconstrói a dicotomia sexo/gênero, ou seja, o sexo não é natural, mas pode ser também discursivo e cultural, assim como o gênero tem sido considerado. Assim, se sexo e gênero são socialmente construídos, devem ser considerados a mesma coisa, não havendo distinção entre ambos. Dessa forma, a autora nos leva a pensar no fim da lógica de que dependendo do órgão sexual da criança, ela será menina ou menino.

Ainda nessa concepção, ao tratar o sexo como natural e o gênero como construído, é aceitar também que o gênero seja essência do sujeito. O gênero seria também "um ponto relativo de convergência entre conjuntos específicos de relações, cultural e historicamente convergentes" (BUTLER, 2012, p. 29).

Para Butler (2003), a hipótese de um sistema binário dos gêneros encerra implicitamente a crença numa relação mimética entre gênero e sexo, na qual o gênero reflete o sexo ou é por ele restrito. Quando o status construído do gênero é teorizado como radicalmente independente do sexo, o próprio gênero se torna um artifício flutuante, com a consequência de que homem e masculino podem, com igual facilidade, significar tanto um corpo feminino como um masculino, e mulher e feminino, tanto um corpo masculino como um feminino. (BUTLER, 2003, p. 24-5).

Nesse sentido, Butler (2003) afirma ainda que nossa linguagem opera em binarismos, de forma que o hegemônico só se constrói em uma oposição necessária a algo inferiorizado e subordinado. Assim, em um exemplo caro aos queer, a heterossexualidade só existe em oposição à homossexualidade, compreendida como seu negativo inferior e abjeto. Ainda que não expressa, a homossexualidade é o outro sem o qual o hegemônico não se constitui nem tem como descrever a si próprio.

\section{A TEORIA QUEER}


A Teoria Queer surge nos Estados Unidos no final da década de 1980, como crítica a estudos da sociologia que tratavam "sobre minorias sexuais e gênero". Esse projeto passou a ter reconhecimento a partir de palestras dadas em Universidades, que tratavam sobre a dinamicidade da sexualidade (MISKOLCI, 2009, p.150).

Nesse sentido:

Teórica e metodologicamente, os estudos queer surgiram de um encontro entre uma corrente da Filosofia e dos Estudos Culturais norte-americanos com o pós-estruturalismo francês, que problematizou concepções clássicas de sujeito, identidade, agência e identificação [...] ainda que haja variações entre os diversos autores, é possível afirmar que o sujeito no pósestruturalismo é sempre encarado como provisório, circunstancial e cindido (MISKOLCI, 2009, p.152).

Já o diálogo com as ciências sociais foi composto por estranhamento e afinidade em prol da compreensão da sexualidade no contexto social e histórico, porque até 1990, a sociologia considerava a ordem social a partir da heterossexualidade. Desse modo, ao rejeitarem o pensamento sociológico, teóricos queer usaram o termo como xingamento e ao mesmo tempo como compromisso no desenvolvimento de uma "analítica da normalização" centrada na questão da sexualidade (MISKOLCI, 2009, p.150, 151).

Com base nos estudos de Foucault (2005), o autor afirma "que a sexualidade não é proibida, antes produzida por meio de discursos", porque a forma de organização e de produção do conhecimento está centrada por parte de quem domina os saberes, tornando a sexualidade objeto de análise de vários estudiosos (MISKOLCI, 2009, p. 153).

Louro (2016), ao tratar sobre o tema em questão, traz alguns conceitos para a expressão Queer, como:

Queer é estranho, raro, esquisito. [...] o sujeito da sexualidade desviante homossexuais, bissexuais, transexuais, travestis, drags. É o excêntrico que não deseja ser 'integrado' e muito menos 'tolerado'. [...] é um jeito de pensar e de ser [...]. Queer é um corpo estranho que incomoda, perturba, provoca e fascina (LOURO, 2016, p. 7-8).

Nesse sentido, podemos compreender que as pessoas inseridas nesses grupos citados pela autora podem ser consideradas estranhas, excêntricas, 
provocantes, fascinantes pelo fato de não estarem em grupos considerados normais pela ordem social, ou seja, pelo sexo ou gênero masculino e feminino, como tradicionalmente se conhece. A expressão queer também é usada para reconhecer pessoas homossexuais e usada por elas em oposição e contestação contra a heteronormatividade (LOURO, 2016).

\section{DISPOSITIVO DA SEXUALIDADE: PRODUÇÃO E GERÊNCIA DE SUJEITOS TRANS}

Segundo Foucault (1998), a sexualidade e suas normas sociais constituem um forte campo de poder em que pessoas e indivíduos são localizados, hierarquizados e punidos, caso fujam às regras. Na sociedade ocidental em que vivemos, há um padrão social de linearidade entre sexo, gênero e desejo.

Foucault (1999) afirma que a sexualidade é um dispositivo que opera por meio de um conjunto heterogêneo que engloba discursos, instituições, organizações arquitetônicas, decisões regulamentares, leis, medidas administrativas, enunciados científicos, proposições filosóficas, morais, filantrópicas.

Desse modo, o dispositivo da sexualidade torna-se mais potente porque opera em um ponto de intercessão do biopoder. A construção dos corpos, regulação das práticas e delimitação dos gêneros multiplica-se no controle da reprodução e em rituais de concepção. Desta feita, as normas sexuais são fundamentais na construção das tecnologias de poder em nossa sociedade, e os desviantes são produzidos enquanto categoria pela mesma estratégia que os pune constantemente.

Foucault (1998) explicita que o poder produz formas de experimentação e vivência da sexualidade como ilegítimas, não para exterminá-las totalmente, mas sim para a manutenção das relações de poder. E acrescenta que o poder "é o nome dado a uma situação estratégica complexa numa sociedade determinada" (FOUCAULT, 1998, p.103). Além disso, o poder se dá em relações, em toda parte, não sendo detido por um único agente.

O autor nos adverte que onde há poder há resistência, o que vai remeter nessa pesquisa ao apelo às mulheres trans vítimas da violência que produzam maneiras alternativas de poder e resistência, agindo como sujeitos livres, uma vez que o autor diferencia relações de poder e de dominação. "As relações de poder não 
podem existir senão em função de uma multiplicidade de pontos de resistência; elas (as resistências) são o outro termo das relações de poder" (FOUCAULT, 1998, p. 91).

Judith Butler (2003), reinterpretando a teoria foucaultiana da sexualidade como dispositivo, questiona como a construção de uma divisão ontológica dos gêneros - que pressupõe a continuação coerente entre sexo, gênero e sexualidade é fundamental para a manutenção de um mundo heterossexual e heterossexista que cria e ordena normas que exigem a inteligibilidade de gênero para que o indivíduo possa ter inteligibilidade social. A desconformidade entre essas categorias reserva às identidades ininteligíveis o status de subumanidade e o locus marginal em que ocupam os abjetos.

Assim, de uma pessoa que tenha um pênis, por exemplo, espera-se que tenha gestos e comportamentos reconhecidos como masculinos e que deseje o corpo de uma pessoa que possua uma genitália oposta a sua (BUTLER, 2003).

Esta linearidade, contudo, é uma invenção social, como nos diz Butler (2003). Ela defende a ideia de que a heteronormatividade é um padrão social instituído que não se sustenta na vida cotidiana concreta. Para a autora, o gênero é:

\begin{abstract}
A estilização repetida do corpo, um conjunto de atos repetidos no interior de uma estrutura reguladora altamente rígida, a qual se cristaliza no tempo para produzir a aparência de uma substância, de uma classe natural de ser (BUTLER, 2003, p. 59).
\end{abstract}

É através destes atos repetidos que o gênero é naturalizado. Nas proposições de Butler (2003), não existe uma linearidade rígida entre sexo, gênero e desejo e tais categorias podem constituir uma complexidade sempre aberta, estabelecida a partir das vivências cotidianas dos grupos sociais, na sua conexão entre tempo e espaço.

Em virtude disso, um dos maiores esforços dos estudos Queer reside na crítica ao que Butler (2012) chama de "heterossexualidade compulsória", isto é, um padrão normativo hegemônico fundado nas relações heterossexuais, as quais são vistas como as únicas reconhecíveis e legítimas. Butler (2012) aborda o conceito de "gêneros inteligíveis" que, segundo ela, são aqueles que instituem e mantém relações e continuidade entre sexo, gênero, prática sexual e desejo. De maneira que, 
certos tipos de identidade de gênero não se conformam às normas de inteligibilidade cultural - a transexualidade, por exemplo - o que as faz parecer falhas no desenvolvimento e com impossibilidades lógicas. As identidades de gênero só se tornam inteligíveis por intermédio de uma única matriz cultural: a heterossexualidade compulsória (BUTLER, 2012).

Por compreendermos que a sexualidade não é algo dado, natural e imutável, mas uma construção histórica e social sobre os modos de sentir e experimentar o corpo, os desejos e as relações, nos basearemos nas contribuições de Foucault (2004) quando afirma que a sexualidade é algo que nós mesmos criamos - ela é nossa própria criação, ou melhor, ela não é a descoberta de um aspecto secreto de nosso desejo.

Berenice Bento, pesquisadora da área do Direito Civil e das Ciências Sociais (2006, p. 132) assevera que a experiência transexual é um dos desdobramentos do dispositivo da sexualidade, sendo possível observá-la como acontecimento histórico. E ressalta, também, tal como Foucault e Butler, o insaciável apetite do discurso médico em dilacerar a experiência transexual, produzindo-a como anomalia a ser tratada e, talvez, 'consertada'. As proposições médicas, todas profundamente ancoradas no dispositivo da sexualidade e na heterossexualidade compulsória, geraram protocolos para o diagnóstico do "verdadeiro transexual" (BENTO, 2006, p. 43), ou seja, aquele ou aquela passível de submissão às cirurgias de redesignação genital. Dessa forma, a experiência transexual é renegada a anomalia mental e, ao ser tomada como patologia após a execução de um longo protocolo médicopsicológico, confere o direito ao sujeito transexual da cirurgia de transgenitalização ou adequação sexual.

\section{POSSIBILIDADES DE ALTERAÇÃO DO NOME POR PESSOAS TRANSEXUAIS}

O nome é um dos direitos da personalidade mais importantes, tendo em vista que o nome é a designação pela qual a pessoa é conhecida no mundo. Nesse sentido, Rosenvald e Farias ratificam: "O nome civil é o sinal exterior pelo qual são 
reconhecidas e designadas as pessoas, no seio familiar e social." (FARIAS e ROSENVALD, 2015, p. 239)

Nesse sentido, Moraes (2000, p. 52) informa:

A relevância do nome, então, não se reduz, como outrora, à designação como pertencente a determinada família. $\mathrm{O}$ nome hoje, conforme a doutrina de Cornu, tende a se "integrar à pessoa até se tornar o sustentáculo dos outros elementos, o anteparo da identidade da pessoa, a sede do seu amorpróprio". Neste sentido, uma nova luz foi trazida pela Psicanálise, ao estabelecer que o nome é suporte não só da identidade social, mas também da identidade subjetiva. (MORAES, 2000, p. 52).

A referida autora ainda acrescenta que o nome não se trata apenas de um direito, sendo também um dever: "Ele é também um dever, o dever que se tem de ser identificado socialmente, cumprindo a função de "sinal distintivo". Aqui o que se leva em consideração é a sua função identificadora do indivíduo, não mais em relação a si mesmo, à sua personalidade e dignidade, mas em relação à comunidade em que se encontra inserido e ao Estado." (MORAES, 2000, p. 54).

$\mathrm{O}$ art. 16 do Código Civil determina: "Toda pessoa tem direito ao nome, nele compreendidos o prenome e o sobrenome". No Brasil, não existe uma lei que regule a identidade de gênero. A LRP, perante o siste $\neg$ ma normativo nacional, é a responsável pelo registro do prenome e gêne $\neg$ ro de uma pessoa em cartório de Registro Civil. Ela usa como parâmetro o sexo biológico, que já se demonstrou falho, para definir o prenome e gênero a ser declarado na certidão de nascimento e demais documentos que se seguirão na vida de uma pessoa (CHAVES, 2000).

Essa norma é extremamente restritiva e admite a substituição de prenome somente em algumas disposições. O artigo 58, por exemplo, consente que seja acrescentado ou suprimido o nome por apelidos públi $\neg$ cos notórios, é o caso das celebridades e dos políticos, bem como admite a permuta visando à segurança de quem tenha sido ameaçado ou coagi $\neg$ do em face de colaboração com a investigação criminal (GARCIA; LAZARI, 2015, p. 97).

Embora o princípio seja a imutabilidade do prenome, considerando-se os artigos 55 e 57, da Lei de Registros Públicos, entende-se que caso o nome imponha constrangimento à pessoa, expondo seu portador ao ridículo, esse poderá ser 
alterado. Por esses termos, essa tem sido a base jurídica utilizada nos pedidos de mudança do nome de transexuais.

Nesses termos, Bento (2014) define a nossa legislação como normativa de caráter autorizativo, visto que sendo o gênero determinado apenas pela "predestinação escrita nos hormônios, o sujeito precisará de especialistas para atestar e fundamentar a autorização de alteração, a sua autodeterminação de identidade de gênero.

Para Bahia e Cancelier (2017), essa realidade tem transformado o procedimento de alteração do nome civil dos transexuais em um processo não só penoso, mas extremamente biologizante, que concede ao juiz um poder de interpretar laudos e escutar testemunhas antes de proferir sua sentença e dar a palavra final acerca da aplicabilidade ou não, no caso concreto, de um direito que é inerente à autoidentidade de gênero.

O nome constitui elemento indispensável para o desenvolvimento da personalidade e que criar empecilhos ao uso do nome compatível com a identidade do seu titular fere diretamente a dignidade da pessoa humana, indo de encontro ao objetivo principal dos direitos da personalidade.

Sucede que da década de 70 adiante, período da publicação da LRP, poucas foram as inserções feitas na mencionada lei. As transforma $\neg$ ções sociais clamam por modificações nas leis e esta não poderia ser dife $\neg$ rente com a identidade de gênero. Compreende-se que a legislação é o alicerce para as decisões judiciais. Ocorre que o regramento legislativo muitas ve $\neg$ zes é omisso e defasado. Nesses casos, o Poder Judiciário, mesmo sem lei, tem que julgar e o socorro terá de vir de institutos como o direito compa $\neg$ rado e os princípios gerais do Direito.

Nesse contexto, a alteração de prenome e gênero sem a imposição de cirurgia é medida de promoção a igualdade social, baseada em valores supremos como o da dignidade da pessoa humana. Dispondo sobre este princípio, tem-se que:

A dignidade da pessoa humana é o valor-base de interpretação de qualquer sistema jurídico, internacional ou nacional, que possa se considerar compatível com os valores éticos, notadamente da moral, da justiça e da democracia. Pensar em dignidade da pessoa humana significa, acima de tudo, colocar a pessoa humana como centro e norte para qualquer processo 
jurídico de interpretação, seja na elaboração da norma, seja na sua aplicação (GARCIA; LAZARI, 2015, p. 97).

Desse modo, depreende-se a relevância do direito à identidade de gênero. Não pode o Estado negar a alteração de prenome e gênero base $\neg$ ando-se em critérios puramente genéticos, haja vista a superação da anᄀtiga distinção homem, gênero masculino versus mulher, gênero feminino.

O direito à identidade da população trans tem alcançado, aos pou $\neg \cos$, relevância e avanços no reconhecimento destes indivíduos como pes $\neg$ soas

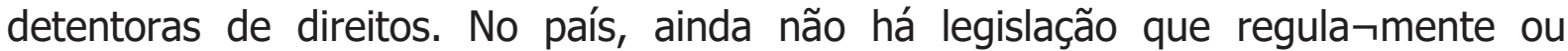
determine a alteração imediata. Assim, resta a trans pleitear a alteração por via judicial. A competência para legislar sobre registros públicos, tanto de pessoas naturais, quando de pessoas jurídicas, registros imóveis e o de título de documentos, segundo a Constituição Federal de 1988, é privativa da União, conforme art. 22, XXV2. A Lei no 6.015/73 (Lei de Registros Públicos), mesmo sendo anterior à constituição, ainda en $\neg$ contra-se em vigor, sofrendo apenas algumas alterações.

O dispositivo legal destaca que os transexuais, inclusive os que não se submeteram à cirurgia transgenital, têm o direito de mudar o gênero no registro civil. Assim entendeu a $4^{a}$ Turma do Superior Tribunal de Justiça, ao reformar decisão do Tribunal de Justiça do Rio Grande do Sul que negou a alteração do sexo e autorizou apenas um novo preno $\neg$ me a uma pessoa que se identifica como mulher. No dia 09 de maio de 2017, durante o julgamento do RESP 1.626.739/RS. O Superior Tribunal de Justiça (STJ) consolidou entendimento no sentido da viabilidade de mudança do nome e do estado sexual do transexual submetido a procedimento cirúrgico de mudança sexual. Para o colegiado, a identidade psicossocial preva-lece em relação à identidade biológica, não sendo a intervenção médica nos órgãos sexuais um requisito para a alteração de gênero em documentos públicos.

Em decisão de 1/03/2018, na Ação Direta de Inconstitucionalidade (ADI) 4.275/2009, o Supremo Tribunal Federal (STF) entendeu ser possível a alteração de nome e gênero no assento de registro civil, mesmo sem a realização de procedimento cirúrgico de redesignação de sexo (BRASIL, 2018a). 
Entretanto, a proteção aos direitos dos grupos vulneráveis a usufruir uma vida digna tem embasamento em decisões recentes das cortes superiores que analisam as questões de discriminação à luz da Constituição Federal, com base no princípio da dignidade da pessoa humana.

A Ministra Nancy Andrighi, do Superior Tribunal de Justiça, em julgado de 18/11/2009, no recurso especial 1008398-SP, decidiu que negar a alteração do prenome do transexual redesignado corresponderia a mantê-lo em uma insustentável posição de angústia, incerteza e conflitos, que a dignidade da pessoa humana deve ser resguardada, em um âmbito de tolerância, para que a mitigação do sofrimento humano possa ser o sustentáculo de decisões judiciais, no sentido de salvaguardar o bem supremo e foco principal do Direito: o ser humano em sua integridade física, psicológica, socioambiental e ético-espiritual.

E acrescenta:

Para o transexual, ter uma vida digna importa em ver reconhecida a sua identidade sexual, sob a ótica psicossocial, a refletir a verdade real por ele vivenciada e que se reflete na sociedade. A falta de fôlego do Direito em acompanhar o fato social exige, pois, a invocação dos princípios que funcionam como fontes de oxigenação do ordenamento jurídico, marcadamente a dignidade da pessoa humana. Em última análise, afirmar a dignidade humana significa para cada um manifestar sua verdadeira identidade, o que inclui o reconhecimento da real identidade sexual, em respeito à pessoa humana como valor absoluto. A situação fática experimentada pelo recorrente tem origem em idêntica problemática pela qual passam os transexuais em sua maioria: um ser humano aprisionado à anatomia de homem, com o sexo psicossocial feminino, que, após ser submetido à cirurgia de redesignação sexual, com a adequação dos genitais à imagem que tem de si e perante a sociedade, encontra obstáculos na vida civil, porque sua aparência morfológica não condiz com o registro de nascimento, quanto ao nome e designativo de sexo. (BRASIL, 2009).

A proteção do direito à sexualidade está diretamente ligada ao reconhecimento da dignidade humana de cada um de forma livre, tendo como base a liberdade e a igualdade, princípios básicos das declarações de direitos humanos e do constitucionalismo clássico. Os direitos sexuais, baseados num modelo socialdemocrático, liberal e laico são fundamentados na autodeterminação, utilizando-se como base a liberdade sexual, liberdade de decisão, o respeito à intimidade e à equidade, e o acesso à informação, aos serviços e a recursos sociais. As políticas públicas de reconhecimento de nome social e o acesso a processos de retificação de 
registro civil visam a garantir a dignidade e a cidadania da população de transexuais, travestis e demais identidades de gênero dissidentes da "cis-heteronormatividade" e à lógica binária das relações de gênero, chamada de binarismo de gênero. (BUGLIONE, 2007)

No Brasil, ainda existe grande resistência na formulação de legislação específica para a alteração do nome e da retificação do registro civil de população transexual, tendo em vista o grande número de pessoas ligadas ao cristianismo no legislativo brasileiro. Os pedidos de retificação de registro civil baseiam-se somente na doutrina atual, bem como na jurisprudência, porém as decisões são baseadas no bom senso do poder judiciário.

A tendência universal é o reconhecimento da identidade de gênero, nela compreendido o direito de retificar prenome e gênero no registro civil, sem que seja necessário recorrer a subterfúgios como a cirurgia para a mudança de sexo.

Compreende-se que o acesso à cidadania para a população trans, no Brasil, ainda é limitado, tendo em vista que não há, até a presente data, legislação específica que trate de garantias e direitos envolvendo identidades de gênero minoritárias, fazendo com que a população trans passe por diversos constrangimentos sociais e psicológicos no convívio em sociedade.

A inexistência de lei específica que dê o direito à retificação de nome e sexo aos indivíduos transexuais e travestis pela diferenciação de seu sexo biológico e sua identidade de gênero tem feito com que diversos órgãos, entidades e corporações criem mecanismos de acesso, median $\neg$ te normativos internos para o uso do nome social.

Na ausência de uma legislação acerca de procedimentos para alteração de nome de pessoas trans, que não se identificam com o nome que consta na sua identidade civil, muitas instituições públicas criaram o que Berenice Bento chamou de "gambiarra legal" (2014), como possível alternativa para a solução de tal problema.

Ocorre que a chamada "gambiarra legal" vem, de fato, trazer um pouco mais de dignidade às trans, uma vez que a necessidade de propositura de ação judicial para alteração do registro civil, com atuação necessária do Ministério Público, tornase muito morosa. 
No âmbito federal, a presidência da República editou em 28 de abril de 2016 o Decreto $n^{\circ} 8.727$, que dispõe sobre o uso do nome social e o reconhecimento da identidade de gênero de pessoas travestis e transexuais no âmbito da administração pública federal, autárquica e fundacional.

A norma define o nome social como a "designação pela qual a pessoa travesti ou transexual se identifica e é socialmente reconhecida." (BRASIL, 2016).

$O$ decreto apresenta 0 procedimento para 0 registro do nome social nas repartições públicas federais e amplia a abrangência de seu uso, visto que, até então, a regulamentação do uso do nome social era elaborada por cada instituição isoladamente. Frise-se que o decreto não é uma norma sobre o nome, mas sobre o "nome social", pois não interfere no registro civil.

Na mesma esteira do decreto presidencial n 8.727/2016, de reconhecer o uso do nome social na Administração Pública Federal, o Presidente do Tribunal Regional Federal da $2^{\mathrm{a}}$ Região, Desembargador Federal André Fontes, editou em 4/10/2018, a Resolução TRF2-RSP-2018/00046, no qual, no art. $1^{\circ}$, assegura a possibilidade de utilização do nome social nos serviços administrativos e jurisdicionais da Justiça Federal nos Estados do Rio de Janeiro e do Espírito Santo:

Art. $1^{\circ}$ Fica assegurada a possibilidade de uso do nome social às pessoas trans, travestis e transexuais usuárias dos serviços judiciários e integrantes do Tribunal Regional Federal da $2^{a}$ Região e das Seções Judiciárias do Rio de Janeiro e do Espírito Santo, notadamente, às partes, aos advogados, aos magistrados, aos servidores, aos estagiários e aos trabalhadores terceirizados, em seus registros, sistemas e documentos, na forma disciplinada por esta resolução. (BRASIL, 2018b).

Para a Resolução TRF2-RSP-2018/00046, o nome social é aquele adotado pelo indivíduo correspondente ao gênero no qual se reconhece, por meio do qual se identifica e é reconhecido na sociedade. O nome social será declarado pela própria pessoa e deverá ser observado independentemente de alteração dos documentos civis. E nos atos praticados por magistrados, servidores e estagiários, será desnecessária a indicação do nome civil, bastando para a identificação o uso do nome social.

Interessante observar que a diretriz na aplicação dessa política pública, abrange também a conscientização e educação de todos os envolvidos na 
manutenção desses valores de promoção da dignidade humana, quando no art. $6^{\circ}$ prevê mecanismos para a formação contínua de magistrados, servidores, estagiários e terceirizados sobre a temática da diversidade sexual e de identidade de gênero.

Art. $6^{\circ}$ A Escola da Magistratura Regional Federal da $2^{a}$ Região (EMARF) e as unidades de Gestão de Pessoas, no âmbito de suas atribuições, promoverão a formação continuada de magistrados, servidores, estagiários e terceirizados sobre a temática da diversidade sexual e de identidade de gênero para a devida aplicação da presente Resolução. (BRASIL, 2018b).

Porém, o nome social só gera efeitos naquelas situações, o indivíduo transexual continua tendo seu direito à identidade de gênero negado. Desse modo, ao ingressar em qualquer ambiente em que o nome social não seja re $\neg$ conhecido, a pessoa passa a ser tratada pelo nome de nascimento, o que não reflete a sua identificação e reitera a violência e discriminação que tais indivíduos sofrem. Por isso, é necessária a criação de uma lei específica que dê embasamento legislativo para as retificações de registro civil, bem como reconheça a identidade trans para dar a essas pessoas condições de se sentirem inseridas na sociedade.

\section{CONSIDERAÇÕES FINAIS}

Este trabalho buscou realizar uma breve discussão sobre a possibilidade de pessoas transexuais conseguirem realizar a alteração do nome e do sexo no Registro Civil. Sobre isso, foi possível compreender que para muitos estudiosos, a questão ser homem ou mulher não significa ser masculino ou feminino necessariamente, mas um pode assumir a identidade do outro e vice-versa ou ir mais além, pois a construção da personalidade se dá através da experiência, das relações com outras pessoas, do desejo, da vivência do dia a dia.

Percebemos que o tema é amplo e envolve muitos outros aspectos, como a posição da Igreja e o olhar de outros segmentos da sociedade, como psiquiatras, antropólogos e educadores, por exemplo e, por outro lado, a atuação da militância e os movimentos LGBT, a pluralização das lutas e a construção de uma comunidade homossexual. Essas questões nos mostram as dificuldades e preconceitos por que passam os grupos dos transexuais e abrem espaço para manifestações desse grupo e seus apoiadores, em busca de igualdade de direitos, contrariando imposições de 
uma ordem social que se diz mais ampla e/ou poderosa, de uma parte da sociedade que não aceita o diferente.

Entretanto, vale ressaltar que independente da opção ou identidade de gênero que cada um deseje seguir, o importante é vislumbrar o valor do ser humano, respeitá-lo e compreendê-lo enquanto participante de uma mesma sociedade, possibilitando uma ampliação de fato no mundo jurídico ao entender as singularidades na multiplicidade da sociedade, efetivando o espaço de todos sem discriminação por raça, cor, etnia, gênero e quaisquer outras.

\section{REFERÊNCIAS}

BAHIA, C. M.; CANCELIER, M. V. de L. Nome social: Direito da personalidade de um grupo vulnerável ou arremedo de cidadania? Revista Húmus, São Luís, v. 7, n. 19, p. 102-123, 2017.

BENTO, B. A reinvenção do corpo: sexualidade e gênero na experiência transexual. Rio de Janeiro: Garamond, 2006.

BENTO, B. Nome social para pessoas trans: cidadania precária e gambiarra legal. Revista Contemporânea, [S.I.], v. 4, n.1, p. 165-182, jan./jun. 2014.

BENTO, B. O que é transexualidade? São Paulo: Brasiliense, 2008.

BRASIL. Decreto $\mathbf{n}^{\circ} \mathbf{8 . 7 2 7}$, de 28 de abril de 2016. Dispõe sobre o uso do nome social e o reconhecimento da identidade de gênero de pessoas travestis e transexuais no âmbito da administração pública federal direta, autárquica e fundacional. Disponível em: http://www.planalto.gov.br/ccivil_03/_Ato20152018/2016/Decreto/D8727.htm. Acesso em: 2 dez. 2018.

BRASIL. Superior Tribunal de Justiça. REsp: 1008398 SP 2007/0273360-5. (3. Turma). Relator: Min. Nancy Andrighi, 15 de outubro de 2009. JusBrasil, [S.I], 2009. Disponível em: https://stj.jusbrasil.com.br/jurisprudencia/5718884/recurso-especialresp-1008398-sp-2007-0273360-5. Acesso em: 12 mar. 2019.

BRASIL. Supremo Tribunal Federal. Ação Direta de Inconstitucionalidade (ADI) 4.275/2009. Relator: Min. Marco Aurélio de Mello, 1 de março de 2018. 2018a. Disponível em:

http://www.stf.jus.br/portal/cms/verNroticiaDetalhe. asp?idConteudo=371085. Acesso em: 2 dez. 2018.

BRASIL. Tribunal Regional Federal da 2a Região. Resolução TRF2-RSP-

2018/00046, de 4 de outubro de 2018. Dispõe sobre o uso do nome social pelas pessoas trans, travestis e transexuais usuárias dos serviços judiciários pelas partes, 
procuradores, magistrados, servidores, estagiários e trabalhadores terceirizados do Tribunal Regional Federal da $2^{a}$ Região e das Seções Judiciárias do Espírito Santo e do Rio de Janeiro. 2018b. Disponível em: http://www10.trf2.jus.br/portal/wpcontent/uploads/sites/28/2018/10/nome-social.pdf. Acesso em: 2 dez. 2018.

BUGLIONE, S. Um direito da sexualidade na dogmática jurídica: um olhar sobre as disposições legislativas e políticas públicas da América Latina e Caribe. In: RIOS, Roger Raupp (Org.). Em defesa dos Direitos Sexuais. Porto Alegre: Editora Livraria do Advogado, 2007.

BUTLER, J. Problemas de Gênero: feminismo e subversão da identidade. Rio de Janeiro: Civilização Brasileira, 2003.

BUTLER, J. Criticamente Subversiva. In: JIMÉNEZ, Rafael M, Mérida (Org.).

Sexualidades transgresoras: uma antologia de estudos queer. Barcelona: Icaria, 2012. v. 1, p. 55-79.

CHAVES, A. Direito à vida e ao próprio corpo: intersexualidade, transexualidade, transplantes. 2. ed. rev. e ampl. São Paulo: Revista dos Tribunais, 2000.

FOUCAULT, M. História da sexualidade: a vontade de saber. Tradução de Maria Thereza da Costa Albuquerque, J. A Guilhon Albuquerque. Rio de Janeiro: Graal, 1998.

FOUCAULT, Michel. Microfísica do Poder. Rio de Janeiro: Graal, 1999.

FOUCAULT, Michel. Michel Foucault, uma entrevista: sexo, poder e a política da identidade. Verve: Revista do NuSol, São Paulo, n. 5, p. 260-277, 2004.

GARCIA, B. P.; LAZARI, R. de. Manual de Direitos Humanos. 2. ed. Salvador, BA: Jus Podivm, 2015.

LOURO, Guacira Lopes. Um corpo estranho: ensaios sobre sexualidade e teoria queer. Belo Horizonte: Autêntica, 2016.

MISKOLCI, Richard. A Teoria Queer e a Sociologia: o desafio de uma analítica da normalização. Sociologias, Porto Alegre, ano 11, n. 21, jan./jun. 2009.

MORAES, Maria Celina Bodin. Sobre o nome da pessoa humana. Revista da EMERJ, Rio de Janeiro, v.3, n.12, 2000.

SÁ, Maria de Fátima Freire de; NAVES, Bruno Torquato de Oliveira. Da autonomia na determinação do estado sexual. In: CORRÊA, Elídia Ap.; GIACOIA, Gilberto; CONRADO, Marcelo (Coord.). Biodireito e dignidade da pessoa humana. Curitiba: Juruá, 2006. 